\title{
DOIS JOGOS DE PENSAR
}

\author{
JOsÉ ARTHUR GIANNOTTI
}

\section{RESUMO}

Qual a relação entre "jogo de verdade" e "jogo de linguagem"? Do primeiro, aproximam-se Heidegger e Foucault, interessados seja na essência da verdade, seja na sua historicidade. Do segundo, Wittgenstein, empenhado em desvendar as condições dos enunciados. Este artigo discorre sobre as implicações desses posicionamentos, procurando enfatizar o papel que neles desempenha a questão do ser.

PALAVRAS-CHAVE: jogo de verdade; jogo de linguagem; Foucault;

Wittgenstein.

\section{SUMMARY}

How are related notions such as "game of truth" and "language game"? The former is associated with Heidegger and Foucault, whose interest is either the essence of truth or its historicity. The latter, with Wittgenstein, who tries to unveil the conditions of meaning of statements. This article discusses the implications of this opposition, emphasizing the role played by the question of being.

KEYWORDS: game of truth; language game; Foucault; Wittgenstein.

Não deixa de ser intrigante que, ao tratar do pensamento, Michel Foucault e Ludwig Wittgenstein se inspirem na atividade do jogo. Mas por que o primeiro sublinha o lado da verdade e o segundo a questão do sentido? Como se distinguem e se entrelaçam "jogo de verdade" e "jogo de linguagem"?

Encarregado de escrever o verbete "Foucault", publicado no Dictionnaire des Philosophes, de Denis Huisman, François Ewald não hesita em recorrer ao mestre e amigo; este, por sua vez, não se faz de rogado, entregando-lhe algumas notas, publicadas posteriormente sob o pseudônimo significativo de Maurice Florance. O filósofo se apresenta como historiador crítico do pensamento, colocando-se assim explicitamente na boa linhagem kantiana. Mais tarde, quando retoma o problema da moral e traz para o primeiro plano a noção de sujeito, começa a flertar com a Fenomenologia do espírito, a liás, livro que costuma abrir aos franceses a porta de acesso a Hegel. No entanto, a despeito de sua luta contra a fenomenologia, é Heidegger, temperado com uma boa dose de pimenta nietzschiana, a fonte principal daquilo que ele entende por pensamento. 
Ao estudar a formação do sujeito falante, particularmente em L'Archéologie du savoir, Foucault toma seqüências como "QWE" - formada pelas primeiras teclas horizontais do teclado português de uma máquina de escrever - como exemplo de enunciado, uma formulação significante mas desprovida de conteúdos semânticos. Muito diferentes, por conseguinte, das proposições que, em geral, se reportam a estados de coisa segundo os valores do verdadeiro e do falso. Estas, além do mais, se articulariam por diferenças pertinentes necessárias ao encontro das referências, tendendo, segundo ele e alguns colegas, a se estruturar num sistema de tipo axiomático. Os enunciados, em contrapartida, se tramam por repetições e diferenças sem pontos de articulação. A filosofia parisiense costuma opor aquela lógica que estaria inteiramente subordinada à identidade, tendendo pois ao automatismo, a um pensamento pela diferença onde a própria verdade se revelaria antes $\mathrm{da}$ oposição dos valores de verdade - o verdadeiro e o falso - característicos da proposição.

Nisso tudo a influência de Heidegger é evidente. Contra o racionalismo que começa a pensar a verdade a partir do adequar, da conveniência entre representação e representado, em suma, da intencionalidade da proposição ao estado de coisa, Heidegger centra sua análise da verdade, podemos assim dizer, no discurso da autenticidade - o "verdadeiro ouro", por exemplo, é aquilo que apresenta seu conceito. Por sua vez, desde que se aceita tomar a predicação, cuja formaé "S é p", como base da linguagem, parece evidente que de uma maneira ou de outra o nome "S" está se reportando a algo ali presente antes de esse nome ser pronunciado. Essa verdade anterior à predicação se resolve assim no desvelamento de algo para um ente que se abre para ela, que está ali, Dasein, abertura para o mundo que marca o ser do homem. O desvelamento da verdade é entendido, então, como fundamento da síntese judicativa e se liga a "comportamentos", a práticas de inserção no mundo.

Vale a pena citar uma frase do próprio Heidegger:

Sem dúvida, enquanto representarmos o pensamento segundo as informações que a lógica nos dá sobre ele, enquanto não levarmos a sério que toda lógica já estáassentada num modo particulardo pensamento - nuncapoderemos considerar com atenção que e até que ponto a poesia - (das Dichten) repousa sobre olembrarpensante (Andenken). ${ }^{1}$

Poesia é tomada aqui como qualquer atividade poética, inclusive a filosofia. Enquanto esse pensamento for regido pela lógica estribada numa forma muito particular do pensamento da identidade, não há meio de compreender como o pensar criador está ligado a uma memória que por sua vez é apresentativa e traz em si um diferente. Heidegger e muitos de seus discípulos não levam em conta a possibilidade de construir uma lógica que não tenha a predicação como base, assim como de formalizar a linguagem cotidiana de muitas maneiras. Ainda se apóiam

[1] Martin Heidegger. "Was heisst Denken". In: Vorträge und Aufsätze, Pfullingen: Neske, 1967. 
[2] Michel Foucault.Ditsetécrits, vol. II. Paris: Gallimard, 2001, p. 454. no pressuposto de que toda proposição possui uma única forma lógica ancorada numa síntese quer de nomes, quer de nome e conceito. Desse ponto de vista é preciso assumir que o fundo do pensamento consiste numa apresentação do nomeado, por conseguinte, numa apresentação de algo que assim pode se fazer ausente, papel sempre atribuído à imaginação e à memória. Mas no percurso de todo esse processo a identidade seria a mesma? Cabe lembrar ainda que o Tractatus, ao manter o pressuposto da unicidade da forma lógica, também se vê obrigado a separar radicalmente o mostrar do dizer, o belo, o bom; o próprio sentido da vida não podendo ser apreendido por aqueles que ainda permanecem no nível da linguagem figurativa. Além disso, confinada a lógica no espaço de uma identidade indiferenciada, não há como evitar uma separação muito nítida entre uma lógica dos sentidos, uma gramática do que se pode dizer com sentido, e uma lógica da verdade, daqueles sentidos que possam ser mostrados eencarnados. Mas e se mostrare pensar julgando forem reciprocamente determinados?

Michel Foucault escapa dessa radical separação entre lógica do sentido e lógica da verdade precisamente quando vê nessa última um jogo. Em poucas palavras: o jogo do verdadeiro e do falso termina por demarcar o próprio campo onde se exercita, o alcance de sua verdade, na medida em que se exerce por meio de técnicas de poder. Nesse ponto nota-se a influência de Georges Canguilhem, que, interessado em estudar, principalmente na biologia, precisa enfrentar como esses conceitos estão sempre se reportando ao jogo das normas e dos fatos, à história da própria verdade, à história dos "discursos verídicos" que se corrigindo e se retificando terminam por desenhar um campo do saber onde passa a valer a oposição entre o verdadeiro e o falso. ${ }^{2}$

No entanto, se o desvelamento está ligado a certas formas de comportamento, ele então não se imbrica irremediavelmente a um comportar-se sobre os outros, entremeando saber e poder? Obviamente a partir daí Foucault pode dar mais peso ao papel formador do podere da técnica, já que um não pode se exercer sem o outro - não à toa, Foucault foi apontado até mesmo como um cripto-comunista.

Essa vinculação entre saber e poder passa a configurar tipos de sujeito e de normas. Numa nota pouco comentada Foucault escreve:

Para Heidegger é a partir da tekhnê ocidental que o conhecimento do objeto selou o esquecimento do Ser. Reviremos a questão e perguntemos a partir de quais tekhnaise formou osujeito ocidental e que foram abertos osjogos da verdade e do erro, da liberdade e do constrangimento que os caracterizam. ${ }^{3}$

A manifestação da verdade, agora entendida como processo de constituir uma objetividade para uma subjetividade, depende de "três elementos fundamentais de toda experiência: um jogo de verdade, as relações de poder e, por fim, as formas de relação consigo mesmo e com os outros". 4 Desse modo, a própria experiência se conforma, em uma 
cultura, na correlação entre campos de saber, tipos de normatividade e formas de subjetividade. O jogo da produção de verdade configura um indivíduo na qualidade de sujeito dessa produção: no nível da linguagem o sujeito falante, no nível das razões o sujeito racional e o louco, no nível do cuidado de si e dos outros, o sujeito moral. Sujeitos que possuem uma história, de sorte que, ao contrário do que pensaram os racionalistas clássicos, a verdade não se dá para o homem de imediato, mas tão-só através de práticas dentre as quais se incluem as práticas de si. Não há produção da verdade sem uma espécie de ascese, de educação do sujeito que se prepara para aceitá-la.

A prática de si se responsabiliza ainda tanto pela formação do sujeito como do objeto, ou melhor, de seu mútuo travejamento, o qual se arma, convém insistir, antes de qualquer síntese característica da predicação. Neste nível profundo, o pensar se resolve nesse mesmo travejamento, pois coloca, em suas diversas relações possíveis, em particular graças a discursos que se ajustam e se verificam, sujeitos e objetos, como se cada lado fizesse do outro seu tema e sua referência, e dele tomasse distância para que nunca o deixasse ao relento.

Se por pensamento se entende o ato que coloca, em suas diversas relações possíveis, um sujeito e um objeto, uma história crítica do pensamento seria uma análise das condições nas quais se formam e se modificam certas relações do sujeito com o objeto, uma vez que estas são constitutivas de um saber possivel. (...) A questão é determinar o que deve ser o sujeito, a que condições ele está submetido, qual o seu status, que posição deve ocupar no real ou no imaginário para se tornar sujeito legítimo deste ou daquele tipo de conhecimento. ${ }^{5}$

[5] Ibidem, p. 1451.

Quem não percebe aqui ecos da Fenomenologia do espírito?

Deixemos, porém, esse processo de formação de sujeitos que culmina na constituição do sujeito moral evoltemos-nos para o conceito de jogo de verdade que, na obra de Foucault, já aparece nos cursos de 1978 e 1979. A determinação recíproca do sujeito e do objeto se faz na medida em que traça, como pano de fundo, o terreno da verdade, onde o verdadeiro e o falso podem se opor e se entranhar. No entanto, dado o radical nominalismo de Foucault, que trata de substituir conceitos como de loucura ou de sexualidade por práticas alinhavando-se para formarem enunciados que podem ser ditos verdadeiros ou falsos repetidamente, toda a história crítica do pensamento deixa de ser a história das aquisições e das ocultações da verdade para vir a ser a história da emergência dos jogos de verdade, daquilo que um sujeito pode dizer decorrente da questão do verdadeiro e do falso. Trata-se, pois, de uma história crítica do pensamento, que não se atém às aquisições nem às ocultações da verdade: é a história da emergência de jogos de verdade, é a história das "veridicções" entendidas como as formas pelas quais se articulam, sobre um campo de coisas, discursos capazes de serem ditos verdadeiros ou falsos. Note-se a intenção anti-heideggeriana: a história crítica do pen- 
[6] Michel Foucault. Naissance delabiopolitique. Paris: Gallimard, 2004, p.35.

[7] Idem. Dits et écrits, vol. II. Paris: Gallimard, 2001, p. 1364.

[8] Idem. Naissance de la biopolitique. Paris: Gallimard, 2004, pp.33-34. samento não tem como meta mostrar os desvelamentos e ocultações do ser, mas um sistema de regras/técnicas que se forma onde o dizer possível e o real possível traçam um campo a priori da experiência. E cabe notar que Foucault não procura a causa responsável pela constituição de uma instância de verificação ${ }^{6}$ mas indicar como, a partir de certo momento histórico, práticas, em geral ditas por um universal de certo modo ilusório, passam a ser pontos de apoio para que se possa dizer overdadeiro ou o falso. Uma análise que sempre partindo de experiências termina por mostrar como elas tecem o campo onde o verdadeiro e o falso podem ser ditos. A tarefa é estudar

... história da verdade, analisar não os comportamentos nem as idéias, não as sociedadesnemsuas "ideologias" massimas problematizações através das quais o serse apresenta como podendo e devendo ser pensado, e as práticas a partir das quais elas se formam. ${ }^{7}$

Examinemos rapidamente um exemplo daquilo que Foucault chama de "lugar de verdade": o mercado. Tal como funciona antes do século XVIII, podemos dizer assim, era lugar de justiça, onde o poder central cuidava para que os preços fossem justos e bem distribuídos entre as partes da população, obviamente respeitando as diferenças estamentais. Em suma, o mercado é lugar de jurisdição. Mas já no século seguinte ele aparece sendo dotado de mecanismos "naturais", onde, por assim dizer, "preços verdadeiros" se constituem e perdem sua dimensão de justiça.Ao revelar essa "verdade" a economia política arma um discurso pelo qual as práticas governamentais serão obrigadas a tomar os preços como padrão de sorte que poderão ser ditas são corretas ou incorretas. Ou ainda:

O mercado, na medida em que, mediante a troca, permite ligar a produção, a necessidade, a oferta, a demanda, o valor, o preço etc. constituinesse sentido um lugar de veridiç̧ão; quero dizer, um lugar de verificação-falsificação para as práticas governamentais. ${ }^{8}$

Note-se que são as práticas governamentais que encontram no mercado seu lugar de verificação. Mas para que tais práticas se tornem racionais precisam levar em conta como o novo sujeito, o homo oeconomicus, se pensa como ser exclusivamente movido por interesses, recusando, portanto, a presença do Estado como regulador dos interesses gerais. Mas esse Estado não pode perder de vista certos fenômenos, como aquele da "população", quelevanta problemas específicos dificilmente levados em conta por uma teoria econômica estritamente liberal. Daí o desdobramento de outro ponto de vista, aquele dos fisiocratas, que, embora partindo igualmente do interesse individual, chegam aos problemas gerais na medida em que vêem o processo de produção como um todo.

As políticas públicas se movem então entre esses dois pólos reguladores, progressivamente verificadas pelo andamento do próprio mer- 
cado. Levando em consideração outros exemplos, percebe-se que Foucault está procurando mostrar como se arma um processo de inteligibilidade do real, como ele vem a ser possível. Já que existem vários regimes veridiccionais, a tarefá é analisar a

constituição de um certo Direito de verdade a partir de uma situação de Direito, a relação Direito e verdade encontrando sua manifestação privilegiada no discurso, o discurso onde se formula o Direito e aquilo que pode ser verdadeiro ou falso; o regime de veridicção não sendo, com efeito, certa lei de verdade, [mas] o conjunto de regras que permitem, a propósito de um discurso dado, fixar quais são os enunciados a serem caracterizados como verdadeiros oufalsos. 9

Em resumo, pensar é problematizar as formas a partir das quais o ser pode ser pensadolevando em conta certas práticas; por exemplo: a problematização da loucura e da doença, feita a partir de práticas sociais e médicas, vai definir certo perfil de "normatização" de seres humanos; a problematização da vida, da linguagem, do trabalho e assim por diante resultam em práticas discursivas obedecendo a certas regras "epistêmicas". ${ }^{10}$

Embora a linguagem também se torne um problema, não vejo como negar que ela desenha o arcabouço de qualquer problematização. Os problemas são falados, ainda que tacitamente. Na tradição de Heidegger, Foucault continua a tomar o pensamento como sendo armado por práticas que, embora articulando o campo de uma dada experiência, terminam por apresentar a base na qual se tece o jogo do verdadeiro e do falso. A explicação é circular, pois o problema se formula numa linguagem que por sua vez vai encontrar o fundamento de seu próprio jogo do verdadeiro e do falso na constituição de uma experiência da própria linguagem como problema. No final das contas, as regras de Direito ditas verdadeiras ou falsas pelo movimento do mercado já possuem sentidos que vão além do Direito comercial. Escrito em latim ou português, um texto de Direito tem suas próprias regras que vão além das regras das línguas em que elas são ditas. Formam um sistema, um travejamento de sentidos definidos uns em relação aos outros e que se reportam a um tipo específico de casos. Ora, os casos das regras do Direito não se confundem com os casos das regras do mercado. Em resumo, Direito e mercado possuem gramáticas próprias. Desse ponto de vista, o exercício de problematizar implica lidar com gramáticas diferentes. O que resta, então, do nominalismo radical de Foucault, se para mostrar como se gera um campo de experiência é preciso recorrer a outros sistemas de regras dotados de gramáticas próprias? A despeito de estarem entranhadas, as condições de sentido não se confundem com as condições de verdade, e não vejo como a experiência da verdade pode armar o horizonte da experiência das significações. Não seria necessário retomar a questão da bipolaridade das proposições?
[9] Ibidem, p. 37.

[10] Michel Foucault. Dits et écrits, vol. II. Paris: Gallimard, 2001, pp. 1364-1365. 
A partir do anos 1930, Wittgenstein abandona a teoria figurativa da linguagem; esta deixa de ser pensada tendo por base proposições elementares constituídas por figurações (Bilden) reportando-se a estados de coisa para ser formada pela integração de múltiplos e variados jogos de linguagem. Um jogo de linguagem é composto por signos ligados às práticas de seus respectivos usos, as quais terminam por mostrar como os próprios signos estão servindo de critério para avaliar se a aplicação dessas regras simbólicas está sendo adequada ou não. Num jogo a mesma regra se aplica indefinidamente mas chega a resultados imprevisíveis, de sorte que o seu uso adequado implica a criação de um halo de diferenças. Estas, por sua vez, se revelam principalmente nas pequenas mudanças de aspecto do "objeto" denotado. No jogo armado entre o pedreiro e o aprendiz, de um lado, variam as palavras-proposições, de outro, os objetos movimentados, mas igualmente o aspecto de um ou de outro. Até que ponto as diferenças de pronúncia e de materiais interferem no curso do jogo? Segue-se que aplicar uma regra traz sempre no horizonte certas regularidades que se mostram quando o próprio jogo é descrito. E isso não precisa acontecer quando começam a emperrar? Toda regra possui, portanto, dois lados:em primeiro lugar, o intencional, empírico; em segundo, aquele que descreve sua gramática, onde seu funcionamento está pressuposto. Sob o primeiro aspecto, ela funciona bipolarmente, sob o segundo, os enunciados descritivos são monopolares. Em resumo, aquela diferença entre predicativo e ante-predicativo habita o enunciado como jogo.

No jogo de verdade, tal como Foucault o entende, as práticas conformam o espaço das "veridicções", mas nada dizem a respeito da alteração desse espaço pela repetição das práticas, nem das condições necessárias de seu uso. Nada além das condições suficientes para sua formação. Uma lógica dialética, nos diz Foucault, joga com termos contraditórios no elemento do homogêneo, enquanto a lógica da estratégia, proposta por ele, "tem por função estabelecer quais são as conexões possíveis entre os ter-

[11] Idem. Naissance de la biopolitique. Paris: Gallimard, 2004, p. 44. mos disparatados e que permanecem disparatados" ${ }^{11}$. Wittgenstein, ao mostrara "mesma" proposição podendo ser empírica, quando se reporta ao mundo, elógica, quando descreve o jogo de linguagem onde se encastoa, não está casando as duas lógicas?

Num jogo de linguagem não há fronteiras nítidas entre o nome, que teria sempre na sua raiz um modo de mostrar apontando, e a frase e a proposição, formadas por signos a que correspondem reações adequadas ou não. Lembremos ainda que, se jogo de linguagem é desde logo pensamento, isso se dá porque seus elementos significantes relativamente simples, verbais ou não, estão ligados a práticas de identificação. Uma regra a que não se ajusta nenhum caso não é uma regra.

Tocamos num ponto de suma importância. Não há regra sem casos, entre eles a relação é interna. Mas no que consiste a diferença entre a 
regra e os casos eentre os casos entre si? Desde os gregos, a regra tem sido considerada como idéia, o visível por excelência, a forma que, como um selo, deixa sua marca na cera da matéria. Não nos cabe aqui examinar como a forma representa a matéria e esta apresenta aquela, mas acredito poder, nesse nível, tocar num ponto nevrálgico do conceito de jogo de verdade e toda a filosofia de Foucault. Enquanto continuarmos a pensar o caso como marca da forma, toda diferença somente pode aparecer como diferença numérica entre os casos ou como o resto que a cunhagem da matéria deixou escapar. Ora, a descoberta de um saber ante-proposicional e pré-representativo permite pensar a diferença e a repetição além do plano em que funcionam a identidade do conceito, a oposição no predicado, a analogia no julgamento e a semelhança na percepção, enfim, além das quatro dimensões que demarcam o mundo clássico da representação e que correspondem às quatro raízes do princípio de razão suficiente. Mas pensar proposições configurando um jogo de linguagem não é negar essa diferença radical entre saber proposicional e o saber da verdade, já que a bipolaridade ou a monopolaridade das proposições dependem de seu uso?

Seria longo demais examinar como essas questões foram tratadas por Michel Foucault e Gilles Deleuze, aliás, em rara sintonia, excepcional quando se leva em conta o tipo de disputa que os filósofos costumam manter entre si, buscando mais a originalidade do que os cruzamentos da reflexão. Cabe-me apontar apenas outro ponto. Enquanto toda a regra estiver sendo pensada como ligada a casos possíveis, a diferença como diferença somente aparece escapando dessa combinação, ela é caso que escapa à regra, que cria caso, que se impõe então como singularidade absoluta, afirmação do extraordinário. Nessas condições só pode se apresentar no plano da verdade, fora do jogo do verdadeiro e do falso. Não haveria, porém, outras formas de sua apresentação?

Voltemos ao conceito de jogo de linguagem. Também ele possui uma genealogia, pois o problema do sentido, a que pretende responder, se impõe quando a linguagem cotidiana começa a emperrar. Somente diante de uma frase mal compreendida é que perguntamos: "O que isso significa?". Mas ninguém repara no sentido quando a frase é enunciada na atitude natural, a não ser que se queira estudar a gramática da língua correspondente. Nos universos muito reduzidos de jogos de linguagem parecidos àquele em que operam o pedreiro e seu aprendiz, nenhum dos atores duvida de que "areia" indica areia, de que um comando deve ser executado, de que o pedreiro pede e o aprendiz obedece e assim por diante. $\mathrm{O}$ jogo se exercita num plano em que inúmeras certezas não são postas em questão, não são problematizadas, assim como não são evidenciadas - estão ali, prontas para mostrar o que são quando questionadas. Mas se ao invés de receber areia, o pedreiro recebe uma terra arenosa? Esse abalos no exercício da proposição e das certezas sem fronteiras que permitem seu funcionamento não valem para qualquer jogo de linguagem, inclusive para a própria linguagem como um complexo emara- 
[12] Ludwig Wittgenstein. Über Gewissheit - On certainty. Nova York: Harper, 1969

nhado de jogos mais simples de linguagem? Não é possível fazer aqui uma análise pormenorizada do livro Sobre a certeza ${ }^{12}$, onde essas questões são amplamente examinadas por Wittgenstein, mas vale a pena ressaltar alguns pontos ligados à nossa questão, o que faço sabendo muito bem que assim me distancio da interpretação dominante de sua filosofia. Primeiro, a fala somente se desenvolve se os interlocutores não tiverem grandes dúvidas, por exemplo, a respeito de sua estrutura fonética. As regras determinantes dessa estrutura, enquanto enunciados significativos, somente podem ser examinadas quando o investigador se volta para seus sentidos e deixa na sombra, por exemplo, o estado de coisa a que um deles se reporta. Para saber que em francês existe uma oposição distintiva entre "u" e "ü", não é necessário apontar um exemplo determinado de seu funcionamento; basta saber se as pessoas estão ou não se entendendo. Ora, esse entendimento nunca é completo e nada nos impede de abandonar o pressuposto, de origem platônica, segundo o qual o entendimento de fato se resolveria apreensão precisa de sua matriz. O primeiro postulado a ser afastado, portanto, é o princípio da determinação completa como responsável pela determinação das individualidades, pois um elemento é relativamente simples sem que se possa afirmar ou negar todos os predicados quelhe cabem. Nãoé por isso, entretanto, que a diferença se apresenta como um diferente irredutível sempre se contrapondo à identidade pressuposta. O diferente forma uma auréola em torno dos casos da regra, daqueles que a confirmam, conforme essa diferença não atrapalhe a intencionalidade do jogo. Emvista dessa intencionalidade, os resultados de cada jogada necessitam de uma dada precisão determinada num intervalo de erros aceitáveis. Mas posto o diferente pelo diferente sem porto de ancoragem, passa-se a admitir o pressuposto platônico invertido: não há jogo com o diferente.

O abandono desses dois limites matriciais - o princípio da completa precisão e aquele outro da diferença absoluta — de modo nenhum impede a comunicação, desde que se leve em contra o próprio processo de constituição da identidade e da diferença no plano das práticas. $\mathrm{Na}$ medida em que a identidade resulta de um processo prático de identificação - e a linguagem não escapa desse condicionamento - os vários sentidos da identidade e os vários sentidos da diferença estão numa determinação recíproca, um não valendo sem o outro no plano prático onde se constituem. Mas ainda é preciso pôr em xeque outro pressuposto: quando se diz que, na língua francesa "u" " "ü" são diferentes fonologicamente, afirma-se uma proposição, cuja verdade, se for negada, revela uma alteração no jogo de linguagem do francês. $O$ jogo se transforma $e$ os indivíduos precisam encontrar um modo de se entender se pretendem distinguir "por baixo" (au dessous) de "por cima" (au dessus). Um jogo de futebol onde o atacante, em certas ocasiões, pudesse arremessar com as mãos, é muito parecido com o futebol de nossos dias, mas não deixa também de ser diferente dele. Daí ser possível dizer que os enunciados que descrevem o funcionamento de jogos de linguagem, que descre- 
vem suas regras, são proposições deessência, obviamente isentas do jogo da bipolaridade. Enfim, tudo o que descreve um jogo de linguagem pertencendo à lógica, se instala como por proposições de essência.

Para ser descrito, o jogo de linguagem necessita ser visto de outra perspectiva daquela em que se apresenta em seu funcionamento normal, ele muda de aspecto antes de tudo para quem diz essa descrição. A mudança de aspecto de cada enunciado, para que ele mostre suas leis deessência, coloca entre parênteses sua história e toda sua genealogia. Não há dúvida de que a história do enunciado, como ele se transformou em regra técnica ou moral, por exemplo, pode estar motivando o dizer, mas o motivo não se confunde com o critério no que a regra se resolve quando se reporta a seus casos. E mesmo quando a regra se transforma conforme o resultado de suas aplicações, essa temporalidade entre o enunciado da regra e o exame de como os casos se enquadram nela desaparece quando ela se mostra outra vez como regra. Em resumo, entre a regra pressuposta $e$ aquela reposta para que dê conta das diferenças indesejáveis dos casos, isto é, no exercício da regra como juízo, abre-se um tempo que, todavia, vem a ser posto entre parênteses quando qualquer regra se coloca como regra em exercício. A mudança de aspecto da regra enunciada quando ela passa a ser examinada para ser descrita, do ponto de vista de suas proposições de essência, anula a temporalidade da origem como critério para que se diga se a regra foi ou não seguida.

Cabeentão distinguir três aspectos do funcionamento de uma regra. Primeiro, como ela serve de critério para distinguir estados ou comportamentos adequados ou não. Segundo, o que ela pressupõe como indubitável para sua descrição possível. Terceiro, sua própria história, como ela se formou e gerou um tipo de comunicação. Se esse terceiro aspecto por certo elucida variações de seu sentido, não é por isso que traz uma dimensão histórica imediata para seu bom seguimento. Por isso, ao considerar um jogo de verdade na sua qualidade de jogo de linguagem termina por revelar aspectos seus que escapam de qualquer explicação genealógica. Em resumo, toda a história da verdade fica suspensa quando se descreve como a regra se aplica, como o juízo se processa.

JOSÉ ARTHUR GIANNOTTI é professor emérito da FFLCH-USP e coordenador da área de Filosofia e Política do Cebrap.

Recebido para publicação em 26 de junho de 2006. NOVOS ESTUDOS CEBRAP 75, julho 2006 pp. $49-58$ 